\title{
Comparison of Transrectal Prostate Biopsy Results with Histology of Transurethral Resection of the Prostate in Men Undergoing High-Intensity Focused Ultrasound
}

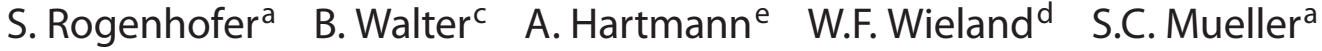 \\ A. Blanab \\ ${ }^{a}$ Department of Urology, University of Bonn, Bonn, ${ }^{b}$ Department of Urology, Hospital of Fürth, Fürth, \\ 'Department of Urology, Hospital of Altötting, Altötting, dDepartment of Urology, St. Josef Hospital, University of \\ Regensburg, Regensburg, and ${ }^{\mathrm{e}}$ Institute of Pathology, University of Erlangen, Erlangen, Germany
}

\section{Key Words}

High-intensity focused ultrasound - Transurethral resection of the prostate - Biopsy - Prostate cancer

\begin{abstract}
Introduction: The aim of our study was to evaluate the significance of transurethral resection of the prostate (TURP) to detect prostate cancer ( $\mathrm{PCa}$ ). A comparison was performed of the TURP specimens of patients undergoing high-intensity focused ultrasound (HIFU) with the core biopsies. Materials and Methods: TURP before undergoing HIFU therapy was performed in 106 patients without neoadjuvant treatment. The resected tissue was subjected to histopathological evaluation and compared to the histological results of transrectal prostate biopsy. Results: Cancer was detected in the resected tissue of 69 patients (65\%). A positive correlation of the amount of resected tissue and detection of PCa could be demonstrated in a multivariate analysis. Conclusions: With a rate of $65 \%$ PCa detected by TURP, our data provide evidence that TURP might be suitable to detect PCa in a small group of selected patients with continuously rising PSA levels and several negative biopsies. On the other hand, these data underline/reinforce the necessity to treat the whole gland using modern treatment modalities such as HIFU and cryotherapy.

Copyright $\odot 2013$ S. Karger AG, Basel
\end{abstract}

C 2013 S. Karger AG, Basel

0042-1138/13/0903-0283\$38.00/0

\section{Introduction}

The technique of systematic random prostate biopsy is still under debate since being described by Hodge et al. [1] 20 years ago. As the potential of overlooking clinically significant cancer has been reported in up to $30 \%$ of cases involving traditional sextant biopsy [2], more extended biopsy techniques are advocated today. Most patients with a negative first biopsy undergo at least one rebiopsy. After two sets of ten or more negative core biopsies it seems that the risk of missing/overlooking cancer in patients with stable PSA levels [3] is acceptably low. Particularly in those patients with rising PSA levels, multiple biopsies are often performed without prostate cancer (PCa) being detected. For such patients, transurethral resection of the prostate (TURP) has been proposed to diagnose PCa that is presumably located in the transitional zone. The detection rate of PCa via 'diagnostic TURP' is as low as $18 \%$ in unselected patients [4]. However, few data support such an approach in preselected patients with a history of negative transrectal biopsies.

Vallancien et al. [5] reported a decrease of urinary catheterization time and an improved post-treatment urinary status without additional morbidity in patients undergoing TURP before high-intensity focused ultra-

\section{KARGER}

E-Mail karger@karger.com

www.karger.com/uin
Dr. Sebastian Rogenhofer

Department of Urology, University of Bonn

Sigmund-Freud-Strasse 25

DE-53127 Bonn (Germany)

E-Mail Sebastian.Rogenhofer@ukb.uni-bonn.de 
Table 1. Patients' baseline characteristics

\begin{tabular}{|c|c|c|c|c|c|c|c|c|c|}
\hline & \multirow[t]{2}{*}{$\mathrm{n}$} & \multirow{2}{*}{$\begin{array}{l}\text { Age, } \\
\text { years }\end{array}$} & \multirow{2}{*}{$\begin{array}{l}\text { PSA, } \\
\mathrm{ng} / \mathrm{ml}\end{array}$} & \multirow{2}{*}{$\begin{array}{l}\text { Prostate } \\
\text { volume, ml }\end{array}$} & \multirow{2}{*}{$\begin{array}{l}\text { Resected } \\
\text { tissue, g }\end{array}$} & \multicolumn{4}{|c|}{ Clinical staging, $\%$} \\
\hline & & & & & & $\mathrm{T} 1$ & $\mathrm{~T} 2 \mathrm{a}$ & $\mathrm{T} 2 \mathrm{~b}$ & $\mathrm{~T} 3$ \\
\hline \multirow{4}{*}{$\begin{array}{l}\text { All patients } \\
\text { With hormonal therapy } \\
\text { Without hormonal therapy } \\
\text { p value }\end{array}$} & 184 & $68.2 \pm 6.5$ & $10.0 \pm 8.3$ & $33.6 \pm 12.0$ & $17.3 \pm 9.4$ & 28.2 & 46.3 & 20.3 & 1.6 \\
\hline & 78 & $67.4 \pm 5.6$ & $11.8 \pm 11.6$ & $33.9 \pm 13.9$ & $18.6 \pm 10.3$ & 36.9 & 38.8 & 19.4 & 2.9 \\
\hline & 106 & $68.6 \pm 6.8$ & $8.6 \pm 4.3$ & $33.4 \pm 9.4$ & $16.3 \pm 8.5$ & 16.3 & 56.8 & 21.6 & 1.4 \\
\hline & & n.s. & n.s. & n.s. & n.s. & n.s. & n.s. & n.s. & n.s. \\
\hline
\end{tabular}

Mean \pm SD; n.s. = not significant.

sound (HIFU) for localized PCa versus HIFU alone. At our institution, HIFU has been routinely combined with TURP since 2001. This group of patients offers a unique pool of histopathological material of core biopsies and prostate tissue from TURP in patients with proven PCa.

The aim of this retrospective study was to investigate the potential of TURP in detecting PCa in patients with diagnosed $\mathrm{PCa}$ and to analyze factors predicting a positive histology from TURP.

\section{Materials and Methods}

Between April 2001 and April 2006, 184 patients with clinically localized PCa were treated with TURP before undergoing HIFU therapy in our department. TURP was performed as in benign prostatic hyperplasia (BPH) cases by resecting the whole transitional zone. For histopathological evaluation, the total resected tissue was processed and investigated by the pathologist.

An indication for the patients to undergo prostatic biopsy was given due to elevated serum PSA, abnormal digital rectal examination (DRE) or abnormal transrectal ultrasonography (TRUS) alone. The patients received a TRUS-guided needle biopsy with at least two cores taken from each lobe. Four to 12 cores were taken at prostate biopsy. Patients with DRE abnormalities were evaluated carefully by TRUS for corresponding lesions. Total prostate volume was calculated: (antero-posterior diameter $\times$ transverse diameter $\times$ longitudinal diameter $) \times 0.60$. Biopsy material was obtained using an automatic biopsy gun with an 18-gauge Tru-Cut. The histopathological evaluation of prostate biopsies was following standard procedures according to published guidelines [6]. All biopsies were processed separately and at least six serial section levels were investigated. Grading was done according the Gleason system in TURP specimens and biopsies. Because all biopsies were investigated before the publication of the currently used modification of the Gleason score (GS) system [7], this system was not used in the present study.

To eliminate a potential bias, we excluded the 78 patients (42\%) who had received a previous hormone therapy. Statistical analysis was performed only for the 106 patients who had not received neoadjuvant treatment prior to biopsy and TURP.

Statistical analyses were performed using the SPSS software version 17.0 (SPSS, Inc., Chicago, Ill., USA). The differences be- tween two dependent variables were tested using the two-sided non-parametric Mann-Whitney U test. A multivariate Cox proportional hazards regression model was used to estimate the prognostic relevance of prostate volume, volume resected, PSA, clinical stage, number of samples with carcinoma and neoadjuvant hormonal therapy on cancer detection by TURP. p values $<0.05$ were considered statistically significant.

\section{Results}

Patients' baseline characteristics are given in table 1 . The median time between the TRUS-guided core biopsy and TURP was 1 month (range $0-9$ ). The median prostate volume before TURP was $32 \mathrm{ml}$ (range 14-72). The mean weight of the resected prostatic tissue was $16.3 \pm 8.5 \mathrm{~g}$. In patients where PCa could be verified by TURP, median $10 \%$ (range $1-80 \%$ ) of the resected prostatic specimen was infiltrated by tumor. There was no positive correlation between prostatic volume and PCa detected by TURP. All patients had undergone at least one preoperative TRUS-guided core biopsy. The distribution of patients according to age, prostate size and amount of resected tissue was statistically not significantly different in the group with PCa-positive TURP and negative TURP.

$\mathrm{PCa}$ was detected by biopsy in the right lobe in 27 (25.5\%) patients and in the left lobe in $45(42.5 \%)$ patients. 29 (27.3\%) patients had positive biopsy cores on both sides of the prostate. In $5(4.7 \%)$ of the patients, no information is available concerning the side of the positive biopsy core. In patients with positive TURP, the number of patients with positive biopsy cores in both lobes was not significantly higher, being $29.0 \%$ (20 of 69 patients).

The mean PSA level before TURP was $8.6 \pm 4.3 \mathrm{ng} / \mathrm{ml}$. Mean PSA in patients with positive TURP and in patients with negative TURP was $7.3 \pm 3.7$ and $9.2 \pm 4.5 \mathrm{ng} / \mathrm{ml}$, respectively. In patients with a high PSA $>10 \mathrm{ng} / \mathrm{ml}, \mathrm{PCa}$ 
Table 2. GS of biopsy and of TURP specimens

\begin{tabular}{lccc}
\hline & Biopsy & TURP & \\
\hline GS $<6$ & $49(46.2 \%)$ & $30(28.3 \%)$ & \\
GS 6+7 & $50(47.2 \%)$ & $28(26.4 \%)$ & \\
GS $>7$ & $2(1.9 \%)$ & $4(3.8 \%)$ & \\
No GS & $5(4.7 \%)$ & $7(6.6 \%)$ & \\
Medium GS sum & $5.3 \pm 1.4$ & $5.7 \pm 1.3$ & $\mathrm{p}=0.357$ \\
\hline
\end{tabular}

Table 3. Multivariate analysis of factors affecting cancer detection by TURP

\begin{tabular}{llll}
\hline Parameters & Hazard ratio & $95 \%$ CI & p value \\
\hline PSA & 1.027 & $0.977-1.079$ & 0.296 \\
Resected tissue & 0.945 & $0.895-0.998$ & 0.044 \\
Prostate volume & 0.995 & $0.956-1.035$ & 0.806 \\
$\begin{array}{l}\text { Number of cores taken } \\
\text { T stage }\end{array}$ & 0.988 & $0.841-1.160$ & 0.879 \\
$\quad$ & & & \\
$\quad$ T1a & reference & reference & reference \\
T1b & 0.000 & & 0.974 \\
$\quad$ T2a & 1.860 & $0.185-18.679$ & 0.598 \\
$\quad$ T2b & 2.423 & $0.315-18.647$ & 0.395 \\
Neoadjuvant hormonal/ & 1.050 & $0.114-9.699$ & 0.966 \\
$\quad$ & 0.381 & $0.176-0.823$ & 0.014 \\
\hline
\end{tabular}

could be detected significantly more often than in patients with low PSA $<10 \mathrm{ng} / \mathrm{ml}(\mathrm{p}=0.033)$.

Overall, PCa was detected in the resected prostatic tissue of TURP in 69 patients (65\%). Out of these patients, $30(28.3 \%)$ had a GS $<6,28(26.4 \%)$ had a GS of 6 or 7 , and $4(3.8 \%)$ showed a high GS of $8-10$. In 7 cases the histological differentiation was not specified (table 2).

Median GS in TURP specimens was $5.7 \pm 1.3$ compared to the median GS of $5.3 \pm 1.4$ in the core biopsy $(\mathrm{p}=0.357)$. The GS was higher in the TURP specimens compared to the tissue of the prostate core biopsy in 29 patients (48\%), the same as in 17 patients (28\%), and lower in 14 patients (23\%). There was no significant correlation between a low or medium GS in biopsy and cancer detection by TURP ( $\mathrm{p}=0.068)$, neither was it possible to demonstrate a statistically significant correlation between positive TURP and prostate size or number of positive cores $(\mathrm{p}=0.80 ; \mathrm{p}=0.87)$. No correlation could be found between the localization of the positive core biopsies (right lobe, left lobe or both lobes) and a positive TURP $(p=0.67)$. It was, however, possible to demonstrate a positive correlation of the amount of resected tissue and de- tection of PCa by TURP. It was possible to evaluate this significance in a univariate $(\mathrm{p}=0.035)$ and a multivariate analysis $(\mathrm{p}=0.044)($ table 3$)$.

$78(42 \%)$ of the patients received short-term hormonal therapy prior to TURP and HIFU treatment. Hormonal therapy had no significant influence on the amount of PCas diagnosed in the tissue obtained via TURP.

\section{Conclusions}

TRUS-guided biopsy is the gold standard in PCa detection. The chance of detecting PCa decreases after each negative biopsy set. In the European Prostate Cancer Detection Study, the incidence of detecting PCa was $22 \%$ in patients with a PSA value ranging from 4 to $10 \mathrm{ng} / \mathrm{ml}$. The second round of biopsies in this large study detected an additional $10 \%$ of cancers. The chance of finding PCa after the second biopsy decreases dramatically [3]. There is evidence that saturation biopsies are helpful to detect $\mathrm{PCa}$ in patients where multiple sets of biopsies have failed. Kawakami et al. [8] were able to diagnose PCa in $37 \%$ of patients with prior negative biopsies by combining transrectal and perineal biopsies taken at the same time. Literature on PCa detection by TURP is rare, therefore the indication for a surgical approach suitable to detect cancer remains unclear.

Ornstein et al. [9] reviewed patients who had symptomatic obstructive $\mathrm{BPH}$ with associated elevated PSA levels or suspicious DRE and a history of at least one benign prostate biopsy. This group detected cancer in $16.1 \%$ of the TURP specimens. In unselected patients, TURP was responsible for the detection of $10 \%$ of all new PCa cases in the Utah Cancer Registry [10] in the late 1990s. Niesel et al. [11] investigated patients with $\mathrm{BPH}$ undergoing simultaneous TURP and biopsy and found that in 27 (19.7\%) of 132 patients, the TURP specimens and biopsies were positive for cancer. Cancer was detected by biopsy alone in only 1 of 27 cases. However, carcinoma was found by TURP alone in 11 out of 132 patients. It is, however, important to note that patients with $\mathrm{BPH}$ were examined.

In contrast to the existing data, our study demonstrated that the incidence of PCa detected by TURP is higher (65\%) than estimated if carcinoma is present in the prostate gland. The difference may stem from the initial clinical profiles of patients who were studied. To the best of our knowledge, all previously published studies looked at the PCa detection rate of TURP in patients with unknown course of increased PSA levels. In contrast, our study investigates the value TURP to detect cancer in a prostate gland with biopsy-proven PCa. 
Therefore, our results are not comparable with previous studies. We can assume that a PCa that is undetected by multiple biopsies will be located at an atypical site, like the ventral section. If this is true, it is not surprising that, in such a location, cancer will not be detection during TURP. The opposite could be true for our population. A PCa diagnosed by standard biopsy is most likely located in the peripheral zone or the transitional zone and thus it might be easier to detect the cancer by the loop during transurethral resection.

Zigeuner et al. [12] showed that on the basis of both a regular DRE and normal PSA levels, the rate of incidental PCa detected by TURP was only $7.4 \%$. One would expect a higher incidence of $\mathrm{PCa}$ in patients with elevated PSA levels. This estimation could be supported by our data, showing a significantly higher cancer detection rate by TURP in patients with PSA levels $>10 \mathrm{ng} / \mathrm{ml}$. Bratt [13] postulated that in patients with a symptomatic $\mathrm{BPH}$, a standard resection of all adenomatous tissue, including the anterior parts, should be performed. In patients without a symptomatic obstruction, the same author discussed that it could be an advantage to make a small resection to minimize the risk of complications, such as capsular perforation and bladder neck sclerosis, which would increase the risk of side effects from later radical treatment. In our collective, we performed an extended TURP (16.3 g of $32 \mathrm{ml}$ ) and found a significant correlation between resected tissue and cancer detection. The concept of an extended TURP is different to the previously published literature and might be a reason why we detected a much higher number of incidences of PCa. Given this significant correlation, we conclude that an extended TURP should be performed in conjunction with diagnostic TURP.

While TURP can frequently detect cancer even in cases with negative biopsies, it may reveal that some of the cancers are clinically insignificant, as postulated in a study by Kitamura et al. [14]. They detected small-volume cancer in 2 of 18 patients who underwent radical prostatectomy after TURP $\left(0.49\right.$ and $\left.0.36 \mathrm{~cm}^{3}\right)$. In contrast to these results, Ornstein et al. [9] reported that $89 \%$ of patients positive for cancer by TURP had clinical stage T1b or a more extended stage. Niesel et al. [11] evaluated 8 patients who underwent radical prostatectomy after detection of PCa by TURP and revealed that none of the PCas diagnosed could be considered insignificant.

Given the fact that some cancers are missed even with extended biopsy protocols [15], saturation biopsy has been explored, resulting in substantial cancer detection rates even after negative biopsies [16]. Although initial investigators used regional or general anesthesia, the periprostatic block permits routine use in office settings. In contrast, TURP must be performed under general or spinal anesthesia. Because our cohort included no patients with previous saturation biopsies, further studies have to be performed to compare the efficacy of saturation biopsy with 'diagnostic TURP'. Perineal template biopsy is another promising technique to identify even small PCa lesions. The detection rate of all significant cancers $\left(>0.5 \mathrm{~cm}^{3}\right)$ is $98 \%$ with this technique that requires anesthesia in all patients [17]. Today, imaging modalities such as elastography, histoscanning, MRI and others have improved the detection rate of PCa biopsies [18-20]. Therefore the role of TURP in diagnosing PCa is even more questionable.

Another potential shortcoming of TURP repeatedly mentioned in the literature is the risk of complicating the later radical prostatectomy operation. However, other sources claim that radical prostatectomy is only slightly more difficult after TURP than routine cases and mediumterm results in terms of continence are fully acceptable.

Heung et al. [21] reported the risk of provoking neoplastic spreading during TURP by dissemination of PCa cells. Similarly, Moreno et al. [22] reported a hematogenous dissemination of prostate cells caused by transrectal biopsy. Although theoretically single tumor cells might be disseminated by TURP or prostate biopsy, long-term clinical surveys showed no increased amount of tumor recurrence or metastasis. Dissemination of tumor cells is even reported in radical prostatectomy without inducing metastasis [23].

Another interesting aspect of our study is the fact that GSs were underestimated by biopsy compared with the TURP findings. The biopsy and TURP results only corresponded well for the mid-range GSs (4-6), which is why nowadays the modified GS system for prostate biopsies published in 2003 [24] is used, avoiding the frequent underestimation of GS in biopsies.

The concept of focal therapy is being given increasing consideration with minimally invasive treatment modalities such as HIFU and cryotherapy. Different concepts such as hemiablation of the prostate, sparing of lateral rims, treatment of an index tumor as well as sparing of the urethra are being tested. Our study proved that $65 \%$ of the patients had PCa within the transitional zone that was resected by TURP. With this knowledge, the concept of sparing the urethra and its surrounding tissue is problematic at least in an unselected population with limited biopsies like ours.

There are some shortcomings of our study. One is the retrospective character of the analysis. A further draw- 
back is the fact that the patients did not have repeated biopsy or saturation biopsy before TURP because a preselected patient group with known PCa was investigated. Also the fact that very inhomogeneous biopsy protocols were applied by different referral urologists makes interpretation of our findings more difficult. Because of these restrictions, our data do not support a clear recommendation of 'diagnostic TURP' as a routine procedure, but there is some evidence that TURP might be considered in selected patients.

The cancer detection rate of $65 \%$ in patients with previously known PCa provides some evidence that a 'diagnostic TURP' can be recommended in some selected patients with continuously rising PSA level and at least two negative biopsies. It remains unclear whether the high detection rate of $65 \%$ in patients with previously known $\mathrm{PCa}$ is some evidence for a 'diagnostic TURP' or whether it is because the TURP has a much better chance of detecting a cancer located in the peripheral zone or the transitional zone that was previously detected by a normal prostate biopsy.

One should therefore carefully analyze the biopsy previously performed and consider if there are still areas not sampled that could be reached with transrectal core biopsy before considering a 'diagnostic TURP'. Because of the significant correlation of resected tissue and cancer detection, we concluded that an extended TURP should be performed if a 'diagnostic TURP' is carried out. On the other hand, our data show that a focal treatment of the prostate gland, sometimes discussed in modern treatment modalities like HIFU and cryotherapy, cannot be recommended.

\section{References}

1 Hodge KK, McNeal JE, Terris MK, Stamey TA: Random systematic versus directed ultrasound-guided transrectal core biopsies of the prostate. J Urol 1989;142:71-74.

2 Keetch DW, Catalona WJ, Smith DS: Serial prostatic biopsies in men with persistently elevated serum prostate specific antigen values. J Urol 1994;151:1571-1574.

-3 Djavan B, Mazal P, Zlotta A, et al: Pathological features of prostate cancer detected on initial and repeat prostate biopsy: results of the prospective European Prostate Cancer Detection Study. Prostate 2001;47:111-117.

4 Pacelli A, Bostwick DG: Clinical significance of high-grade prostatic intraepithelial neoplasia in transurethral resection specimens. Urology 1997;50:355-359.

5 Vallancien G, Prapotnich D, Cathelineau X, Baumert H, Rozet F: Transrectal focused ultrasound combined with transurethral resection of the prostate for the treatment of localized prostate cancer: feasibility study. J Urol 2004;171:2265-2267.

6 Van der Kwast TH, Lopes C, Santonja C, et al: Guidelines for processing and reporting of prostatic needle biopsies. J Clin Pathol 2003; 56:336-340.

7 Epstein JI, Allsbrook WC Jr, Amin MB, Egevad LL: The 2005 International Society of Urological Pathology (ISUP) Consensus Conference on Gleason Grading of Prostatic Carcinoma. Am J Surg Pathol 2005;29:12281242.

$\checkmark 8$ Kawakami S, Okuno T, Yonese J, et al: Optimal sampling sites for repeat prostate biopsy: a recursive partitioning analysis of three-dimensional 26-core systematic biopsy. Eur Urol 2007;51:675-682.
9 Ornstein DK, Rao GS, Smith DS, Andriole GL: The impact of systematic prostate biopsy on prostate cancer incidence in men with symptomatic benign prostatic hyperplasia undergoing transurethral resection of the prostate. J Urol 1997;157:880-883.

10 Merrill RM, Wiggins CL: Incidental detection of population-based prostate cancer incidence rates through transurethral resection of the prostate. Urol Oncol 2002;7:213-219.

11 Niesel T, Breul J, Hartung R: Diagnostic value of additional systematic prostate biopsies in patients undergoing transurethral resection of the prostate. Urology 1997;49:869-873.

12 Zigeuner R, Schips L, Lipsky K, et al: Detection of prostate cancer by TURP or open surgery in patients with previously negative transrectal prostate biopsies. Urology 2003; 62:883-887.

13 Bratt O: The difficult case in prostate cancer diagnosis - when is a 'diagnostic TURP' indicated? Eur Urol 2006;49:769-771.

14 Kitamura H, Masumori N, Tanuma Y, et al: Does transurethral resection of the prostate facilitate detection of clinically significant prostate cancer that is missed with systematic sextant and transition zone biopsies? Int J Urol 2002;9:95-99.

15 Epstein JI, Walsh PC, Carter HB: Importance of posterolateral needle biopsies in the detection of prostate cancer. Urology 2001;57: 1112-1116.

16 Stewart CS, Leibovich BC, Weaver AL, Lieber MM: Prostate cancer diagnosis using a saturation needle biopsy technique after previous negative sextant biopsies. J Urol 2001;166: 86-91.
17 Barzell WE, Melamed MR: Appropriate patient selection in the focal treatment of prostate cancer: the role of transperineal three-dimensional pathologic mapping of the prostate - a 4-year experience. Urology 2008;70(suppl):27-35.

18 Smeenge M, Barentsz J, Cosgrove D, et al: Role of transrectal ultrasonography in focal therapy of prostate cancer: report from a consensus panel. BJU Int 2012;110:942-948.

19 Salomon G, Spethmann J, Beckmann A, et al: Accuracy of HistoScanning ${ }^{\mathrm{TM}}$ for the prediction of a negative surgical margin in patients undergoing radical prostatectomy. BJU Int 2013;111:60-66.

20 Dickinson L, Ahmed HU, Allen C, et al: Magnetic resonance imaging for the detection, localisation, and characterisation of prostate cancer: recommendations from a European consensus meeting. Eur Urol 2011;59:477494

21 Heung YM, Walsh K, Sriprasad S, Mulvin D, Sherwood RA: The detection of prostate cells by the reverse transcription-polymerase chain reaction in the circulation of patients undergoing transurethral resection of the prostate. BJU Int 2000;85:65-69.

22 Moreno JG, O’Hara SM, Long JP, et al: Transrectal ultrasound-guided biopsy causes hematogenous dissemination of prostate cells as determined by RT-PCR. Urology 1997;49: 515-520.

23 Ogawa O, Iinuma M, Sato K, et al: Circulating prostate-specific antigen mRNA during radical prostatectomy in patients with localized prostate cancer: with special reference to neoadjuvant hormonal therapy. Urol Res 1999; 27:291-296.

-24 Kunz GM Jr, Epstein JI: Should each core with prostate cancer be assigned a separate Gleason score? Hum Pathol 2003;34:911-914. 